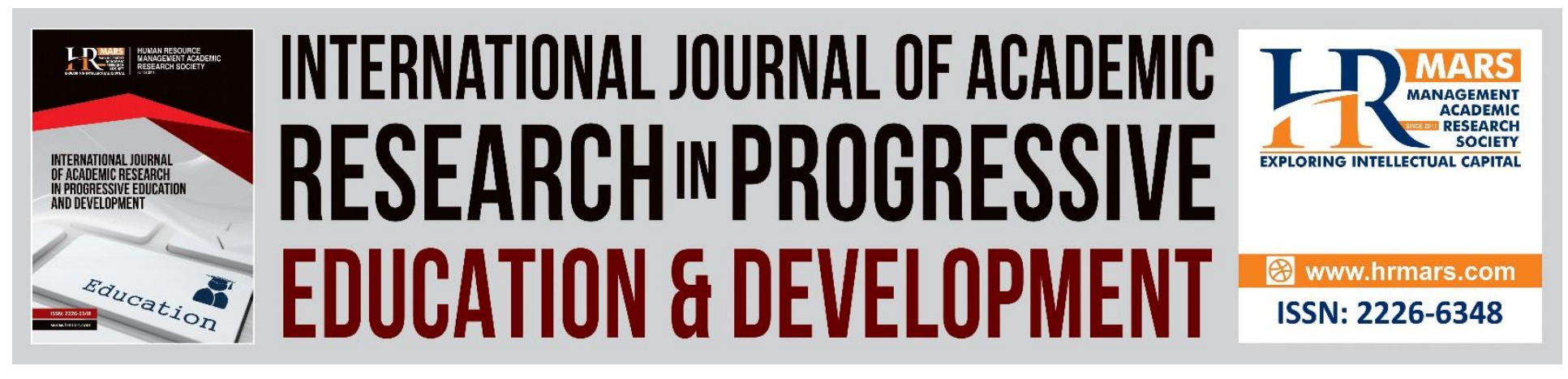

\title{
Comparison of Students' Academic Performance in Mathematics Course with Synchronous and Asynchronous Online Learning Environments during COVID-19 Crisis.
}

Zuraira Libasin, Ahmad Rashidi Azudin, Nur Azimah Idris, Mohd Syafiq Abdul Rahman and Norazah Umar

To Link this Article: http://dx.doi.org/10.6007/IJARPED/v10-i2/10131

DOI:10.6007/IJARPED/v10-i2/10131

Received: 01 April 2021, Revised: 04 May 2021, Accepted: 27 May 2021

Published Online: 11 June 2021

In-Text Citation: (Libasin et al., 2021)

To Cite this Article: Libasin, Z., Azudin, A. R., Idris, N. A., Rahman, M. S. A., \& Umar, N. (2021). Comparison of Students' Academic Performance in Mathematics Course with Synchronous and Asynchronous Online Learning Environments during COVID-19 Crisis. International Journal of Academic Research in Progressive Education and Development, 10(2), 492-501.

Copyright: (C) 2021 The Author(s)

Published by Human Resource Management Academic Research Society (www.hrmars.com)

This article is published under the Creative Commons Attribution (CC BY 4.0) license. Anyone may reproduce, distribute, translate and create derivative works of this article (for both commercial and non-commercial purposes), subject to full attribution to the original publication and authors. The full terms of this license may be seen at: http://creativecommons.org/licences/by/4.0/legalcode

Vol. 10(2) 2021, Pg. 492 - 501

http://hrmars.com/index.php/pages/detail/IJARPED

JOURNAL HOMEPAGE

Full Terms \& Conditions of access and use can be found at http://hrmars.com/index.php/pages/detail/publication-ethics 


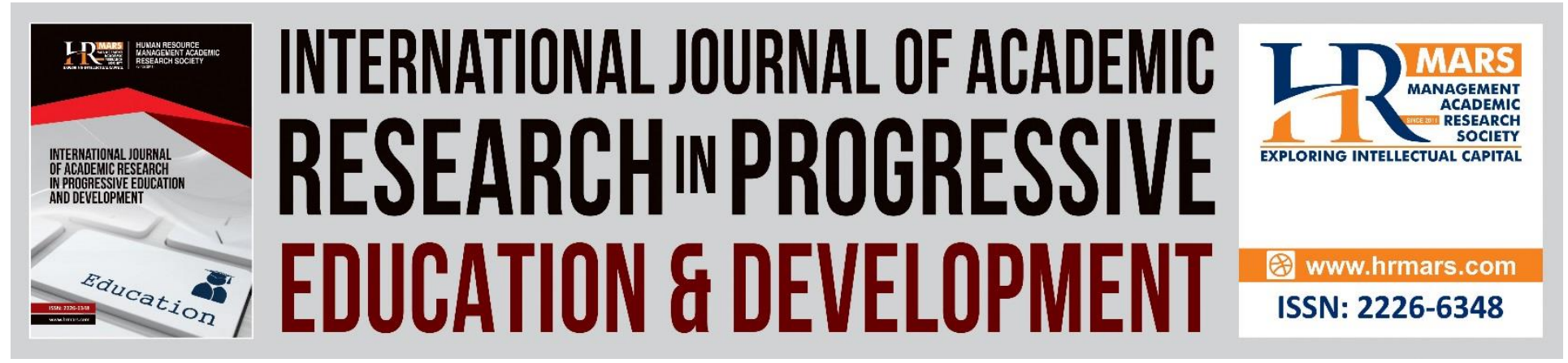

\title{
Comparison of Students' Academic Performance in Mathematics Course with Synchronous and Asynchronous Online Learning Environments during COVID-19 Crisis.
}

\author{
Zuraira Libasin, Ahmad Rashidi Azudin, Nur Azimah Idris, Mohd \\ Syafiq Abdul Rahman and Norazah Umar \\ Department of Computer \& Mathematical Sciences, Universiti Teknologi MARA Cawangan \\ Pulau Pinang, Malaysia
}

\begin{abstract}
There are two categories in which educator can deliver open distance learning (ODL) via an internet connection, namely Synchronous Online Learning (OL-sync) and Asynchronous Online Learning (OL-async). At Universiti Teknologi MARA Cawangan Pulau Pinang (UiTMCPP), lecturers could conduct ODL in OL-sync or OL-async due to MCO which was enforced on March 18, 2020. Therefore, this study was conducted to compare the influence of different learning styles with OL-sync and OL-async on UiTMCPP students' academic achievement during the COVID-19 crisis. This study will present the data analysis of research quantitatively. Independent sample ttest is going to employ, and the result indicates a significant difference between the mean of the two online learning approaches with a significant value of 0.004 . Therefore, we can conclude that the OL-synch approach gives better result in students' academic performance. It is consistent with the findings of Duncan (2012), which recommend that online learning of the synchronous approach will give a better academic performance for the students.

Keywords: Academic Performance, Synchronous, Asynchronous, Online Learning, COVID-19

\section{Introduction}

The rapid transmission of the COVID-19 has ignited global concern. As a precautionary measure to curb this outbreak, the Malaysian government announced the closure of educational institutions during the enforcement of the Movement Control Order (MCO). This scenario has changed the educational landscape and posed new challenges for educators and students in Malaysia. They have to adapt to new norms and expectations. Undergo new practices in the teaching and learning (T\&L) process to ensure that the educational activities can still resume. Thus, open and distance learning (ODL) is no longer a choice but a necessity.
\end{abstract}


According to Mohamad et al (2010), as cited in the Malaysian Qualifications Agency (2013), ODL refers to "the provision of flexible educational opportunities in terms of access and multiple modes of knowledge acquisition". The term flexible means alternatives are available to acquire education at any time, anywhere and through anyways. The term access means an opportunity provided to all to make them free from the constraints of time and place. Multiple modes mean the utilization of a multitude of ways to deliver educational activities and content. Generally, the students can implement the ODL via e-mail, social media applications, live chat, learning management system, or video conferencing tools that require the internet connection. If students have difficulties with internet access, they can use other offline channels such as mail or post, voice message, short message, telephone, radio, or television as alternatives. ODL, as the name suggests, carries the features of learning and teaching with the separation of instructors from learners by time and space. Its mission aims to provide greater flexibility in the aspect of access, curriculum, or other elements of structure (UNESCO, 2002).

There are two categories in which educator can deliver ODL via an internet connection, namely Synchronous Online Learning (OL-sync) and Asynchronous Online Learning (OL-async). Singh and Thurman (2019) interpreted the term online learning (OL) as learning experiences using various devices such as smartphones and computers with internet support in synchronous or asynchronous approaches. The synchronous approach means that the learning process happens in real-time, which requires the engagement of the instructor and the students at the same time but can be from different locations. To the contrary, the asynchronous approach does not require real-time interaction. Based on the concept of online learning, it suggests that the learning process can be implemented anywhere that has internet connectivity with the use of specific devices. For areas with stable and high-speed internet connectivity, it is recommended to conduct remote learning using synchronous support tools such as Google Meet or Cisco Webex. However, for areas with unstable internet access, they can use asynchronous support tools such as Google Classroom or Padlet as an alternative to remote learning. T\&L can also be executed by recording videos and audios and then uploading them to platforms such as WhatsApp, Telegram, YouTube, or e-mail to share with students.

Several studies have been conducted examining how different learning styles influence learners' academic performance and perception of education. Duncan et al (2012) examined the relationship between MBA students' performance and participation in synchronous and asynchronous online learning environments. They reported that the quality and quantity of student's participation in synchronous interaction had a higher statistical significance on overall course grade as compared to asynchronous interaction. Meanwhile, Buxton (2014) completed a study on pharmacists' perception of synchronous and asynchronous distance learning. The study involved 82 students who were divided into two groups which enrolled one group in synchronous online learning and another group in asynchronous online learning. The study showed that the participants in the asynchronous course were delighted and rated their learning experiences more positively. To assess if there was a significant differentiation between synchronous and asynchronous students for end-of-course grades, the PhD thesis presented by Berry (2017) compared educational outcome results from online Algebra 1 courses. The research revealed 
Vol. 10, No. 2, 2021, E-ISSN: 2226-6348 @ 2021 HRMARS

that there were slightly lower end-of-course grades and standardized test scores for synchronous students than for asynchronous students.

There may not be sufficient relevant literature for engineering students enrolled in a Mathematics course to compare their academic performance using different learning styles between OL-sync and OL-async. According to Yadav (2017), mathematics is divided into two branches such that pure and applied mathematics. He states that instead of using knowledge in practical ways, pure mathematics is concerned with the growing understanding of the subject, i.e. its learning is theoretical. Using knowledge of pure mathematics is affected with applied mathematics. It is not realistic, just hypothetical (Yadav, 2017).

At Universiti Teknologi MARA Cawangan Pulau Pinang (UiTMCPP), lecturers could conduct ODL in OL-sync or OL-async due to MCO which was enforced on March 18, 2020. Table 1 illustrates the benefits and weaknesses of OL-sync and OL-async. The existing traditional mode of learning, however, shows that face-to-face communication between students and instructors or classmates is still vital to avoid misunderstandings in the delivery and receiving of knowledge. Moreover, it also helps them to exchange views and ideas more effectively. Therefore, this study was conducted to compare the influence of different learning styles with OL-sync and OL-async on UiTMCPP students' academic achievement during the COVID-19 crisis.

Table 1. Advantages and disadvantages of OL-sync and OL-async

\begin{tabular}{|c|c|c|}
\hline $\begin{array}{l}\text { Mode of } \\
\text { Learning }\end{array}$ & Benefits & Weaknesses \\
\hline OL-sync & $\begin{array}{l}\text { - Promotes positive instructor- } \\
\text { student relationships as students } \\
\text { feel connected to their peers and } \\
\text { instructors (Watts, 2016). } \\
\text { - Allows learners to gain } \\
\text { instantaneous feedback from the } \\
\text { instructor and their peers (Strang, } \\
\text { 2013). }\end{array}$ & $\begin{array}{l}\text { - Learners may miss out on important } \\
\text { information if they have problems with } \\
\text { the internet connection as synchronous } \\
\text { support tools require high internet } \\
\text { bandwidth to operate. } \\
\text { - Could lead to students' frustration with } \\
\text { scheduling as they have to be online at } \\
\text { a particular time (Falloon, 2011). }\end{array}$ \\
\hline OL-async & $\begin{array}{l}\text { - Offers flexibility in which learners } \\
\text { can learn at their own pace } \\
\text { (Buxton, 2014). } \\
\text { - Allows learners to engage more } \\
\text { deeply with the study materials as } \\
\text { they have more time to reflect on } \\
\text { their ideas (Stein et al., 2009). }\end{array}$ & $\begin{array}{l}\text { - Learners who are not highly self- } \\
\text { motivated may face a problem as this } \\
\text { learning style requires them to be self- } \\
\text { disciplined. } \\
\text { - Learners may feel isolated from the } \\
\text { learning environment as social } \\
\text { interactions with the instructors, and } \\
\text { their peers are limited (Hrastinski, 2008). }\end{array}$ \\
\hline
\end{tabular}

To ensure teaching and learning process run smoothly during the pandemic, lecturers must accommodate themselves with the new environment of fully online learning, whether it is synchronous or asynchronous. As a face-to-face approach, it is a difficulty for many, and blended learning is frequently used before the pandemic. Ernest and Hopkins (2006) stated that online 
Vol. 10, No. 2, 2021, E-ISSN: 2226-6348 @ 2021 HRMARS

learning indeed is highly labour intensive, in need of considerable time investment for the preparations of materials and demanding close contact between the lecturers and faculties to assure that all students receive accurate information.

\section{Methodology \\ Participants}

OL-sync and OL-async approaches have become important as teaching medium during the COVID-19 crisis. The participants examined in the study were students enrolled for Mathematics course, offered in the Department of Computer \& Mathematical Sciences, UiTMCPP, in the semester of March - July 2020. The students taking the course online were on campus as well as off-campus students. It depended to the lecturer to select either OL-sync or OL-async, based on a few requirements. The requirements are including the speed and the choice of the students' internet connection to enrol in the class. The study consisted of 262 students, 147 of whom were preferred for the OL-sync approach, and 115 were preferred for the OL-async approach. The method used for OL-sync in this study was by using Google Meet while for OL-async, it consists of Google Classroom, WhatsApp, Telegram and Padlet.

\section{Implementation of OL-sync}

Google Meet

Google Meet is the closest app to the face-to-face method where lecturers are able to interact with the students in real-time. Lecturers can read the students facial expression to determine their level of understanding while having a spontaneous question and answer session. However, this app burdens the students since it requires high data consumptions.

\section{Implementation of OL-async}

Google Classroom

Google Classroom is an educational app that is user friendly and lighter than Google Meet. This free app has systematic assignment management and grading system. Lecturers can share learning materials in various type of files through Google Meet that has been integrated into Google Classroom.

\section{WhatsApp and Telegram}

WhatsApp (Zulkanain et al., 2020) and Telegram are among the most popular messaging apps used to share information. Studies also found that students prefer to use WhatsApp for learning purposes. Students give good feedbacks about their studies through WhatsApp (Chear, 2017). WhatsApp is suitable to be used as a learning platform as it can work on low-speed internet access (Muriati, 2020). Therefore, learning materials such as video content should be uploaded in short and compact.

\section{Padlet}

Padlet is an online application used for content distribution and content curation (Zainuddin et al., 2020). Padlet allows user to drag-and-drop materials in the page. It is a simple app that does not require installation because it can be accessed through internet browsers. It is interactive 
and flexible. Hence, suitable to encourage students for collaboration and sharing ideas. Padlet supports various type of files such as text, images, videos, links and many others that can be uploaded and transmitted. Students can interact among themselves in the page to comment or discuss regarding the sharing.

\section{Data Analysis}

This study will present the data analysis of research quantitatively. Independent sample t-test is going to employ to examine the influence of different learning styles with OL-sync and OL-async on UiTMCPP students' academic achievement during the COVID-19 crisis. The significance levels were set at $p<0.05$ for all analyses. Quantitative data were analyzed using SPSS.

\section{Result and Discussion}

The results are depicted here in both visual and numerical fashions. The quantitative analysis of the results revealed in Figure 1 that lecturers conduce to use the OL-synch approach rather than the OL-asynch approach, where the percentage for both online learning approaches are $56 \%$ and $44 \%$ respectively. This preference is made by asking the students' capability towards online learning since the government introduced MCO because of COVID-19 crisis.

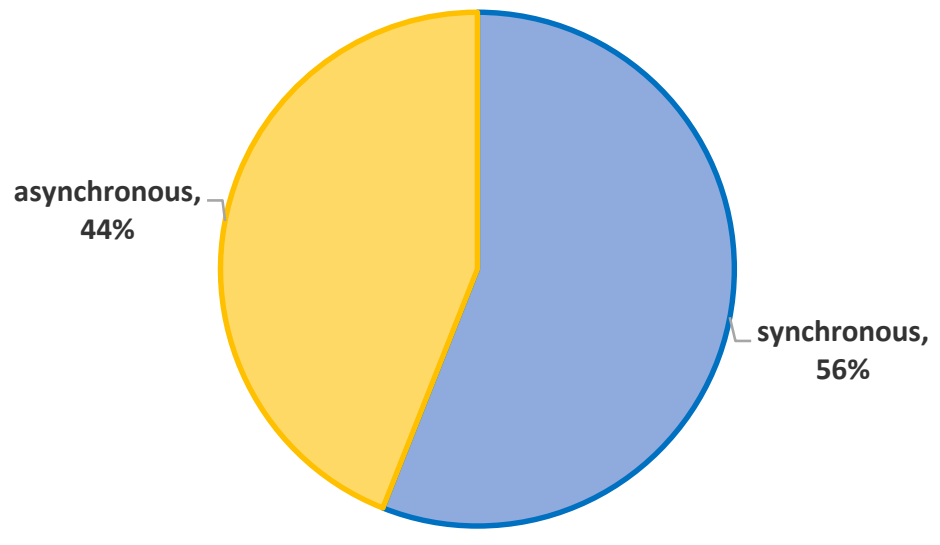

Figure 1. Students' preferences for choosing the online learning approach.

More detail analysis is required to determine the significant differences among these two online learning approaches towards students' performance. Table 2 illustrates the percentage of success and failure, according to grades. The passing grade is from A to $C$, whereas the failing grade is from $C$ - to $F$. The result indicates that the passing difference percentage is 3.67 , which is hard to conclude the significant difference between the percentage of the success and failure of these two methods. On the other hand, by looking at the failure percentage, OL-synch seems to be the best approach since its failure percentage is lower than the OL-asynch. Therefore, to ensure these are correctly understood, further detail analysis is done to verify the result from table 2 by using students' final examination score. 
INTERNATIONAL JOURNAL OF ACADEMIC RESEARCH IN PROGRESSIVE EDUCATION AND

DEVELOPMENT

Vol. 10, No. 2, 2021, E-ISSN: $2226-6348$ @ 2021 HRMARS

Table 2. Percentage of success and failure for the two methods

\begin{tabular}{|c|c|c|c|c|c|}
\hline & \multicolumn{2}{|c|}{ OL-synch } & \multicolumn{2}{|c|}{ OL-asynch } & \multirow[b]{2}{*}{ Difference Percentage } \\
\hline & Number & Percentage & Number & \begin{tabular}{|l} 
Percentage \\
\end{tabular} & \\
\hline Success & 145 & 99.32 & 110 & 95.65 & 3.67 \\
\hline Failure & 2 & 0.68 & 5 & 4.35 & \\
\hline Total & 147 & & 115 & & \\
\hline
\end{tabular}

Scores for the two methods are collected and analyzed using SPSS. Table 3 shows that the mean of both approaches is slightly different, where the mean for OL-synch is 79.31 and OL-asynch 74.86.

Table 3. Mean result for both approaches

\begin{tabular}{|l|l|l|l|}
\hline & Method & Sample size,N & Mean \\
\hline Scores & OL-synch & 147 & 79.31 \\
\hline & OL-asynch & 115 & 74.86 \\
\hline
\end{tabular}

It would be helpful to support the result in Table 3 by performing an independent samples t-test to see whether there is a significant difference in mean marks between the two methods.

Table 4. Independent samples t-test

\begin{tabular}{|l|l|l|l|l|l|}
\hline \multicolumn{2}{|c|}{} & \multicolumn{2}{l|}{$\begin{array}{l}\text { Levene's Test for } \\
\text { Equality of variances }\end{array}$} & \multicolumn{4}{l|}{ t-test for Equality of Means } \\
\cline { 3 - 6 } \multicolumn{2}{|c|}{} & Sig. & t & df & Sig. (2-tailed) \\
\hline \multirow{2}{*}{ Scores } & Equal variances assumed & 0.272 & 2.900 & 260 & $\mathbf{0 . 0 0 4}$ \\
\cline { 2 - 6 } & Equal variances not assumed & & 2.842 & 222.953 & 0.005 \\
\hline
\end{tabular}

The outcome in Table 4 shows the significant difference between the mean of the two ways with a significant value of 0.004 . Therefore, we can conclude that the OL-synch approach gives better result in students' academic performance. It is consistent with the findings of Duncan (2012), which recommend that online learning of the synchronous approach will give a better academic performance for the students. On the other hand, it is in contrast with previous studies by Berry (2017) and Buxton (2014). It is probably because of the courses. Different courses need different approaches to online learning. One of the main challenges for the lecturers is to provide the best learning resources to the students. Kaup et. al (2020) suggests that hybrid learning which is a combination of OL-sync and OL-async, will be more effective in teaching and learning process. The most preferred method by lecturers has pre-recorded videos, and some lecturers even upload the videos on YouTube then later share the links. Online classroom live meeting through applications such as Google Meet, Zoom and Meet in Microsoft Teams are then used to enhance understanding through discussions between lecturers and students. Nevertheless, it is still infeasible for lecturers to keep track of each students' comprehension of the course in the case of a large group of students in a class.

Another concern is academic dishonesty among students in their assessments' submissions. Assessment is essential and a vital element in grading the students. It also serves as a tool to track 
the students' development and understanding of the course. Rowe (2004) mentions that there are various methods of cheating, and it is unavoidable and thus raises significant security issues. Hence, lecturers must opt to have a trust-based relationship with the students even though there are always rooms for suspicions.

Students' self-discipline, as well as technology literacy and competency to adapt to the new environment, will determine whether online learning is a hit or a miss for them. They need to have a peer-like class that support each other, consistent and reliable help from lecturers as well as continuous discussion of the course throughout their studies (Dennen \& Wieland, 2007). The survey of Shaikh and Raval (2020) states that online learning gives students more space to study at their convenience regardless of time and place to accommodate their learning needs. Besides, introvert and passive students need to step up their courage and be more progressive during class discussions to ensure that their class participation is noticed and their voices are heard.

Besides that, the major challenge is the internet connection. Some students reside in a rural area where internet connections are scarce (Chear, 2017), while some may have financial difficulty to afford a high-speed internet connection. The disadvantage students especially the ones from a poor background who may not afford to own the suitable gadgets and internet connectivity for online learning may suffer and therefore could not access the online materials prepared by their respective lecturers (Jena, 2020).

There are many platforms available online for teaching and learning. Some students are lost as lecturers shift all their course content and materials to their preferred online platforms as they need to get used to each of their lecturers' platforms. Mukasa-Lwanga (2018) concludes that "variations of web-based technologies used by individual lecturers would derail the achievement of study objectives". Thus, the institutions need to encourage their lecturer to use the institutions' respective e-learning platforms as well as limit the number of online platforms used.

\section{Conclusion}

Students and lecturers should work together to ensure that learning will proceed as before but in the new norm. The application of OL-sync and OL-async approaches have become important as teaching medium during the COVID-19 crisis in UiTMCPP. The result concludes a significant difference between the mean of the two ways with a significant value of 0.004 . Therefore, we can conclude that the OL-synch approach gives better result in students' academic performance. It is consistent with the findings of Duncan (2012), which recommend that online learning of the synchronous approach will give a better academic performance for the students. Still, it is in contrast with previous studies by Berry (2017) and Buxton (2014). It is probably because of the courses. Different courses need different approaches to online learning. This poses an area for future work where UiTMCPP will use the hybrid learning which is a combination of OL-sync and OL-async, so that there will be more effective in teaching and learning process as suggested by Kaup et. al (2020). 
INTERNATIONAL JOURNAL OF ACADEMIC RESEARCH IN PROGRESSIVE EDUCATION AND

DEVELOPMENT

Vol. 10, No. 2, 2021, E-ISSN: 2226-6348 @ 2021 HRMARS

\section{Acknowledgement}

The completion of this undertaking could not have been possible without the participant and assistance of so many people whose names may not all be enumerated. Their contributions are sincerely appreciated and gratefully acknowledged. However, the group would like to express their deep appreciation and indebtedness, particularly to Assoc. Prof. Ts. Dr Ahmad Zia UI-Saufie Mohamad Japeri and Ts. Jamal Othman for their endless support, kind and understanding spirit to this paper.

\section{Corresponding Author}

Zuraira Libasin. Department of Computer \& Mathematical Sciences, Universiti Teknologi MARA Cawangan Pulau Pinang, Malaysia. Email: zuraira946@uitm.edu.my

\section{References}

Buxton, E. C. (2014). Pharmacists' Perception of Synchronous Versus Asynchronous Distance Learning for Continuing Education Programs. American Journal of Pharmaceutical Education, 78(1), 8.

Duncan, K., Kenworthy, A., \& McNamara, R. (2012). The Effects of Synchronous and Asynchronous Participation on Students' Performance in Online Accounting Courses. Accounting Education, 21(4), 431-449.

Falloon, G. (2011). Making the Connection: Moore's Theory of Transactional Distance and its Relevance to the Use of a Virtual Classroom in Postgraduate Online Teacher Education. Journal of Research and Technology in Education, 43(3), 187-209.

Hrastinski, S. (2008). A Study of Asynchronous and Synchronous e-Learning Methods Discovered that Each Supports Different Purposes. Educase Quaterly, 4, 51-55. Retrieved from https://er.educause.edu/articles/2008/11/asynchronous-and-synchronous-elearning.

Singh, V., \& Thurman, A. (2019). How Many Ways Can We Define Online Learning? A Systematic Literature Review of Definitions of Online Learning (1988-2018). American Journal of Distance Education, 33(4), 289-306.

Stein, D. S., Calvin, J., \& Wanstreet, C. E. (2009). How a Novice Adult Online Learner Experiences Transactional Distance. The Quarterly Review of Distance Education, 10(3), 305-311.

Strang, K. (2013). Cooperative Learning in Graduate Student Projects: Comparing Synchronous Versus Asynchronous Collaboration. Journal of Interactive Learning Research, 24(4), 447464.

UNESCO. (2002). Open and Distance Learning: Trends, Policy and Strategy Consideration. Paris: UNESCO.

Watts, L. (2016). Synchronous and Asynchronous Communication in Distance Learning: A Review of the Literature. Quaterly Review of Distance Education, 17(1), 23-32.

Zulkanain, N. A., Miskon, S., \& Abdullah, S. N. (2020). An adapted pedagogical framework in utilizing WhatsApp for learning purpose. Educ Inf Technol 25, 2811-2822

Zainuddin, N. M. M., Azmi, N. F. M., Yusoff, R. C. M., Shariff, S. A., \& Hassan, W. A. W. (2020). Enhancing Classroom Engagement Through Padlet as a Learning Tool: A Case Study. International Journal of Innovative Computing, 10(1). 
INTERNATIONAL JOURNAL OF ACADEMIC RESEARCH IN PROGRESSIVE EDUCATION AND

\section{DEVELOPMENT}

Vol. 10, No. 2, 2021, E-ISSN: 2226-6348 @ 2021 HRMARS

Shaikh, F., \& Raval A. (2020). Online learning give out the advantage and Challenges. Journal of Information and Computational Science, 10(7), 731-735.

Ernest, P., \& Hopkins, J. (2006). Coordination and Teacher Development in an Online Learning Environment. CALICO Journal, 23(3), 551-568.

Kaup, S., Jain, R., Shivalli, S., Pandey, S., \& Kaup, S. (2020). Sustaining academics during COVID-19 pandemic: The role of online teaching-learning. Indian Journal of Ophthalmology, 68(6), 1220-1221.

Rowe, N. C. (2004). Cheating in online student assessment: Beyond plagiarism. Online Journal of Distance Learning Administration, 7(2).

Yadav, Dharmendra. (2017). Exact definition of mathematics. International Research Journal of Mathematics, Engineering and IT. 4. 34-42.

Berry, S. (2017). Educational Outcomes of Synchronous and Asynchronous High School Students: A Quantitative Causal-Comparative Study of Online Algebra 1. ProQuest LLC, Ed.D. Dissertation, Northeastern University 